\title{
Brief research report: sociodemographic factors associated with HIV status among African American women in Washington, DC
}

This article was published in the following Dove Press journal:

International Journal of Women's Health

18 September 2013

Number of times this article has been viewed

\author{
Emory L Perkins' \\ Dexter R Voisin ${ }^{2}$ \\ Kesslyn A Brade Stennis' \\ 'Department of Social Work, \\ Bowie State University, Bowie, \\ MD, USA; ${ }^{2}$ School of Social Service \\ Administration, University \\ of Chicago, Chicago, IL, USA
}

Introduction: African American women living in Washington, DC have one of the highest Human immunodeficiency virus (HIV) incidence rates in the US. However, this population has been understudied, especially as it relates to factors associated with HIV status.

Methods: This cross-sectional study examined sociodemographic factors that were associated with having a negative or positive HIV status among a sample of 115 African American women between the ages of 24 and 44 years. We assessed such factors as age, education, sexual orientation, household income, sources of income, number of children, length of residency tenure in Washington, DC, and level of HIV-prevention knowledge.

Results: Among the overall sample, 53 women self-identified as HIV-positive and 62 as HIV-negative. Compared to their HIV-negative counterparts, women who reported being HIVpositive were less educated, had lower household income, and had longer residency tenure in Washington, DC. There were no differences in HIV knowledge between HIV-positive and -negative study participants.

Conclusion: These findings may provide important directions for targeting specific subpopulations of African Americans for HIV-prevention/intervention programs.

Keywords: HIV status, African American women, sociodemographic factors

\section{Introduction}

In the US, African American communities continue to be disproportionately affected by acquired immune deficiency syndrome (AIDS). For instance, in 2011, rates of Human immunodeficiency virus (HIV) infections among African Americans were $42 \%$, but $12 \%$ for Hispanics/Latinos, $4 \%$ for whites, and 3\% for Asians. ${ }^{1}$ Among all African Americans, women continue to be disproportionately infected by $\mathrm{HIV}^{1}$ and are 15 times more likely than their white female counterparts to be HIV-infected. ${ }^{1}$ More importantly, heterosexual African American women living in Washington, DC report some of the highest HIV rates in the country, with rates that have doubled from $6.3 \%$ in 2008 to $12.1 \%$ in $2010 .{ }^{1}$ Despite these epidemic rates of HIV infections among African American women, there is a dearth of studies that exclusively focus on this population, and few studies that explore how individual factors may distinguish HIV status among this population. One study that did examine factors associated with HIV status among a multiethnic sample in Washington, DC found that nearly $62 \%$ of all HIV-positive participants were African American making less than \$10,000, and 37\% were unemployed. ${ }^{2}$ These are useful findings. However, it remains unknown what patterns may exist among a racially homogeneous sample of African American women. Additionally, we do not know whether additional individual factors, such as education,
Correspondence: Emory Perkins Department of Social Work, Bowie State University, 1400 Jericho Park Road, Bowie, MD 207I5, USA

Tel +l 30I 8603172

Email eperkins@bowiestate.edu 
sources of income, number of children, length of residency tenure in Washington, DC and HIV-prevention knowledge might be related to HIV status.

Therefore, the primary purpose of this study was to explore how such sociodemographic factors as education, household income, number of children, and length of residency might be related to HIV status among African American women residing in Washington, DC. We examined these factors given that they are related to network concepts and might be proxies for insular arrangements. For instance, women who are unemployed, have a high number of children, and have longer periods of residency might be more embedded within insular social and sexual networks. Such embedded states have been shown to be a significant driver of HIV acquisition. ${ }^{3}$

\section{Materials and methods}

Research assistants were trained college students who recruited potential study participants from local community-based organizations (CBOs) over a 2-week period between August and September 2006. The CBOs selected for recruitment sites provided such services as housing referral, job training and recommendations, and mental health and/or drug counseling. CBOs were selected in neighborhoods where the Washington Department of Public Health noted there were extremely high HIV-infection rates. Participants were eligible for study participation if they were female, self-identified as African American, born in the US, 18 years or older, and provided informed consent. Enrolled participants were given self-administered surveys, which they completed in a private space located within the CBOs, and were compensated $\$ 15$ for study participation. Based on empirical considerations, it was determined that a sample size of 100 would be adequate to detect statistical significance between groups of HIV-positive and -negative participants. Study approval was obtained for all research procedures by the Howard University Institutional Review Board. Howard University is a historically African American university located in Northwest Washington, DC.

\section{Measures}

Age was assessed by one item: "What is your age?" Education was assessed by one item: "What is your education level?" (1, Some high school/high school diploma; 2, some college/ college degree; 3 , postgraduate). Sexual orientation was assessed by one item: "What is your sexual orientation?" (1, heterosexual; 2, homosexual; 3, bisexual). Household income was assessed by one item: "What is your monthly household income?" (1, Less than $\$ 600 ; 2, \$ 600$ to $\$ 1,000 ; 3$, over $\$ 1,000)$. Sources of income were assessed by one item: "What are your sources of income?" (1, Supplemental Security Income/Social Security Disability Insurance; 2, employment wages; 3, unemployment benefits; 4, other source of income). Number of children was assessed by one item: "How many children do you have?" Length of residency was assessed by one item: "How long have you lived in Washington, DC?"

HIV knowledge was assessed by 18 items, ${ }^{4}$ ie, "Showering or washing one's genitals/private parts after sex keeps a person from getting HIV"; "Coughing and sneezing do not spread HIV"; "A person can get HIV by sharing a glass of water with someone who has HIV"; "Pulling out the penis before a man climaxes/cums keeps a woman from getting HIV during sex"; "A woman can get HIV if she has anal sex with a man"; "All pregnant women infected with HIV will have babies born with AIDS"; "People who have been infected with HIV quickly show serious signs of being infected"; "There is a vaccine that can stop adults from getting HIV"; "People are likely to get HIV by deep kissing, putting their tongue in their partner's mouth, if their partner has HIV"; "A woman cannot get HIV if she has sex during her period"; "There is a female condom that can help decrease a woman's chance of getting HIV"; "A natural skin condom works better against HIV than does a latex condom"; "A person will not get HIV if she or he is taking antibiotics"; "Having sex with more than one partner can increase a person's chance of being infected with HIV"; "Taking a test for HIV one week after having sex will tell a person if she or he has HIV"; "A person can get HIV by sitting in a hot tub or a swimming pool with a person who has HIV"; "A person can get HIV from oral sex"; and "Using Vaseline or baby oil with condoms lowers the chance of getting HIV." Response categories for each item were "True" "False" or "Don't know." "Don't know" responses were coded as an incorrect response. Each correct answer was assigned a weighted score and computed to create an overall index (overall mean 40.95, median 41.4, standard deviation [SD] 5.79). In this study the Cronbach's alpha was 0.75 .

HIV status was assessed by one item: "What is your HIV status?" (1, HIV-negative; 2, HIV-positive; 3, don't know). Persons who indicated "don't know" were omitted from the analyses.

\section{Data analysis}

We calculated univariate analyses to describe the overall sample and bivariate statistics to examine group differences between HIV-positive and -negative participants. $t$-Tests were computed for continuous variables, and Chi-squared for categorical variables. All data were analyzed using SPSS version 19.0 (IBM, Armonk, NY, USA). 


\section{Results}

The overall study sample comprised 115 participants. The mean age was 35.2 (SD 7.44) years, and almost half of the participants (42\%) had attended high school or obtained a high school diploma. Additionally, almost half (48\%) of all participants earned monthly incomes over $\$ 1,000$, and $75 \%$ had one child. The average length of residency status in Washington, DC was 4.3 years (SD 5.41).

Table 1 shows differences between HIV-negative and -positive women based on sociodemographic characteristics. We noted no significant age differences between groups. However, HIV-negative participants reported higher levels of education compared to their HIV-negative counterparts $\left(\chi^{2}=11.69, P=0.003\right)$. With regard to sexual orientation, more heterosexual participants indicated they were HIV-positive than their -negative counterparts $\left(\chi^{2}=6.88\right.$, $P=0.032$ ). Income was another dimension that distinguished
HIV status. Interestingly, more HIV-positive women indicated higher incomes than their HIV-negative counterparts $\left(\chi^{2}=19.64, P=0.001\right)$. In addition, more HIV-positive women had longer Washington, DC residency compared to their HIV-negative counterparts (mean 2.2 versus 6.3, $P=0.002)$. Finally, results indicated that levels of HIVprevention knowledge did not differ between groups.

\section{Discussion}

This study examined sociodemographic factors associated with HIV status among African American women living in Washington, DC. Only a handful of studies have examined such factors in this city, despite the high incidence of HIV among African American women. In addition, few studies have explored the compendium of correlates we examined in this study. Prior findings have indicated that sociodemographic factors such as low income and homelessness were

Table I Sociodemographic characteristics of HIV-positive and -negative African American women $(n=1$ I5)

\begin{tabular}{|c|c|c|c|c|c|}
\hline & $\begin{array}{l}\text { HIV-negative } \\
\text { (n) }\end{array}$ & $\begin{array}{l}\text { HIV-positive } \\
\text { (n) }\end{array}$ & $\begin{array}{l}\text { Total } \\
\text { (n) }\end{array}$ & $\chi^{2}$ & $P$ \\
\hline \multicolumn{6}{|l|}{ Age, years } \\
\hline Mean & 34.9 & 35.54 & & & \\
\hline SD & 7.464 & 7.389 & & & \\
\hline \multicolumn{6}{|l|}{ Education } \\
\hline High school & 17 & 31 & 48 & 11.69 & $0.003 * *$ \\
\hline College & 25 & 10 & 35 & & \\
\hline Postgraduate & 18 & 11 & 29 & & \\
\hline \multicolumn{6}{|l|}{ Sexual orientation } \\
\hline Heterosexual & 37 & 53 & 90 & 6.88 & $0.032 *$ \\
\hline Homosexual & 4 & 4 & 8 & & \\
\hline Bisexual & 11 & 3 & 14 & & \\
\hline \multicolumn{6}{|l|}{ Household income } \\
\hline Less than $\$ 600$ per month & 21 & 13 & 34 & 19.643 & $0.001 * * *$ \\
\hline$\$ 600$ to $\$ 1,000$ per month & 12 & 7 & 19 & & \\
\hline$\$ 1,000$ and over & 9 & 39 & 48 & & \\
\hline \multicolumn{6}{|l|}{ Source of income } \\
\hline SSI/SSDI & 15 & 10 & 25 & 3.063 & 0.216 \\
\hline Wages & 17 & 12 & 29 & & \\
\hline Unemployment & 19 & 17 & 36 & & \\
\hline Other & 20 & 21 & 41 & & \\
\hline \multicolumn{6}{|l|}{ Children, $\mathrm{n}$} \\
\hline 0 & 17 & 19 & 36 & 3.678 & 0.159 \\
\hline 1 & 27 & 28 & 55 & & \\
\hline $2-3$ & 12 & 13 & 25 & & \\
\hline 4 or more & 3 & 0 & 3 & & \\
\hline \multicolumn{6}{|c|}{ Length of time residing in Washington DC } \\
\hline Mean & 2.2 & $6.31 * *$ & & & \\
\hline SD & 1.2 & 2.6 & & & \\
\hline \multicolumn{6}{|l|}{ HIV knowledge } \\
\hline Mean & 40.48 & 41.42 & & & \\
\hline SD & 6.42 & 5.16 & & & \\
\hline
\end{tabular}

Notes: $* P<0.05 ; * * P<0.01$; *** $* 0.001$.

Abbreviations: SD, standard deviation; SSI, Supplemental Security Income; SSDI, Social Security Disability Insurance. 
related to an HIV-positive status. ${ }^{5}$ This study contributes to the existing literature and the major findings indicated that education, income, sexual orientation, and length of residency in Washington, DC distinguished more women who reported being HIV-negative from those who were HIVpositive. Given the degree of limited resources noted among this population, it is possible that higher incomes among HIV-positive versus -negative women may reflect greater access to income benefits. For instance, prior findings have indicated that HIV-positive women noted several positive changes over time associated with their diagnoses, such as higher educational levels and greater income. ${ }^{6}$ Nevertheless, our assumption here is purely speculative and would need to be explored in future research.

In addition, we documented that more heterosexual versus bisexual or gay women reported being HIV-positive. This finding confirms that heterosexual African American women bear a higher HIV-acquisition burden. Biological factors, partner characteristics, and having lower power to negotiate condoms with men may partly account for such trends. ${ }^{7,8}$ Interestingly, there were no significant differences with regard to HIV knowledge based on status. In general, African American women have lower levels of HIV-prevention knowledge compared to their peers from other racial/ethnic groups. ${ }^{9}$ In this study, participants indicated HIV-prevention means that ranged from 40.48 to 41.42 , while other studies using the same measure have reported means that ranged from 69.2 to $72.5 .^{8,9}$ Among this study population, such a finding might suggest that HIV-prevention knowledge was relatively lacking, irrespective of HIV status. Therefore, targeted and concentrated HIV-prevention education initiatives are needed for African American women residing in Washington, DC, regardless of their HIV status. Consequently, messages that target both primary and secondary prevention approaches are warranted. In addition, it is important to ensure that such messages are grounded in cultural- and gender-appropriate ways in order to increase their uptake in this population. For instance, a recent study noted that African American females indicated a preference for HIV-prevention information from ethnic-targeted television with messages being delivered by everyday persons to whom they could relate. ${ }^{10}$

Overall, these study findings are important. However, as in all studies, several limitations warrant mentioning. The cross-sectional study design precludes any temporal or causal inferences among variables, and all findings are only suggestive of correlations. Cross-sectional studies are often criticized for their inability to tease out temporal ordering. However, they do establish important preliminary relationships, a contribution which this study offers, which can then form the basis for more costly longitudinal studies. In addition, given our convenience-sampling frame, our findings are only limited to African American women from similar settings, and larger more representative diverse samples would be needed to generalize our findings to a wider cross section of females. While we assessed a broad compendium of HIV correlates, we did not assess religion or marital status, which have been shown to be correlated with HIV status in prior studies. ${ }^{11,12}$ Therefore, future studies should also investigate these factors in addition to the ones assessed in this study.

Finally, though self-report measures are widely used in social science research, they have limitations with regard to validity. This may especially be the case with regard to accurately reporting one's HIV status. We took deliberate steps to reduce response bias to all questions, especially those that were sensitive, by: having participants complete the self-administrated questionnaire in private spaces inside the CBOs; not collecting any identifying information, stressing the confidential nature of the study; and indicating that questions could be skipped at any time. However, response bias is always present with self-report measures. Future studies might use rapid HIV testing to confirm HIV status. Irrespective of these limitations, there is a dearth of studies conducted on African American women living in Washington, DC, and we believe that the findings from this preliminary study can guide future studies on this highly vulnerable high-risk population.

\section{Conclusion}

Despite these limitations, our findings suggest that HIVprevention messages need to target all African American women, given the low level of HIV-prevention knowledge that was pervasive among this study population. Additionally, our findings suggest that heterosexual women continue to be a high priority for HIV-prevention and -intervention campaigns. Among this group, we especially need to target women with lower levels of formal education and those who have longer residency status in Washington, DC.

\section{Disclosure}

The authors report no conflicts of interest in this work.

\section{References}

1. Centers for Disease Control and Prevention. Diagnoses of HIV Infection in the United States and Dependent Areas, 2011. HIV Surveillance Report. Atlanta: CDC; 2013;23. Available from: http://www.cdc.gov/ hiv/library/reports/surveillance/2011/surveillance_Report_vol_23.html. Accessed May 15, 2013. 
2. DC Department of Health HIV Administration. District of Columbia HIV Prevention Plan for 2006-2010. Washington: DC DOH; 2009. Available from: http://www.uchaps.org/assets/dc_hiv_prevention_plan_20062010-1.pdf. Accessed March 7, 2013.

3. Schneider J, Voisin D, Michaels S, Ostrow D, Laumann E. Evaluation of sexual networks as a cause for disparate HIV prevalence between blacks and whites: More questions than answers. AIDS. 2011;25(15):1933-1934.

4. Carey MP, Schroder KE. Development and psychometric evaluation of the brief HIV Knowledge Questionnaire. AIDS Educ Prev. 2002;14:174-184.

5. Adimora AA, Schoenbach VJ, Martinson FA, et al. Heterosexually transmitted HIV infection among African Americans in North Carolina. J Acquir Immune Defic Syndr. 2006;41:616-623.

6. Updegraff JA, Taylor SE, Kemeny ME, Wyatt GE. Positive and negative effectives of HIV infection in women with low socioeconomic resources. Pers Soc Psychol Bull. 2002;28:382-394.

7. Joint United Nations Programme on HIV/AIDS. A Strategic Approach: HIV/AIDS and Education. Geneva: UNAIDS; 2009. Available from: http://unesdoc.unesco.org/images/0016/001627/162723e.pdf. Accessed March 7, 2013.
8. Joint United Nations Programme on HIV/AIDS. Getting to Zero: 2011-2015 Strategy. Geneva: UNAIDS; 2010. Available from: http:// www.unaids.org/en/media/unaids/contentassets/documents/unaidspublication/2010/JC2034_UNAIDS_Strategy_en.pdf. Accessed March 7, 2013.

9. Ebrahim S, Anderson J, Weidle P, Purcell D. Race/ethnic disparities in HIV testing and knowledge about treatment for HIV/AIDS: United States, 2001. AIDS Patient Care STDS. 2004;18:27-33.

10. Voisin DR, Shiu CS, Chan Tack A, Sekulska D, Krieger C, Johnson L. In their own words: racial/ethnic and gender differences in sources and preferences for HIV prevention information among young adults. AIDS Care. Epub March 1, 2013.

11. Trinitapoli J, Mark DR. Religion and HIV risk behaviors among married men: initial results from a study in rural sub-Saharan Africa. J Sci Study Relig. 2006;45:505-528.

12. Shisana O, Zungu-Dirwayi N, Toefy Y, Simbayi LC, Malik S, Zuma K. Marital status and HIV infection in South Africa. S Afr Med J 2004;94:537-543.
International Journal of Women's Health

\section{Publish your work in this journal}

The International Journal of Women's Health is an international, peerreviewed open-access journal publishing original research, reports, editorials, reviews and commentaries on all aspects of women's healthcare including gynecology, obstetrics, and breast cancer. The manuscript management system is completely online and includes

\section{Dovepress}

a very quick and fair peer-review system, which is all easy to use. Visit http://www.dovepress.com/testimonials.php to read real quotes from published authors.

\footnotetext{
Submit your manuscript here: http://www.dovepress.com/international-journal-of-womens-health-journal
} 